\title{
Whole genome SNP arrays as a potential diagnostic tool for the detection of characteristic chromosomal aberrations in renal epithelial tumors
}

Federico A Monzon ${ }^{1,2, *}$, Jill M Hagenkord ${ }^{2,3, *}$, Maureen A Lyons-Weiler ${ }^{1,2}$, Jyoti P Balani ${ }^{1}$, Anil V Parwani ${ }^{1,3}$, Christin M Sciulli ${ }^{2}$, Jia Li ${ }^{4}$, Uma R Chandran ${ }^{3}$, Sheldon I Bastacky ${ }^{1}$ and Rajiv Dhir ${ }^{1}$

${ }^{1}$ Department of Pathology, University of Pittsburgh, Pittsburgh, PA, USA; ${ }^{2}$ Clinical Genomics Facility, University of Pittsburgh, Pittsburgh, PA, USA; ${ }^{3}$ Department of Biomedical Informatics, University of Pittsburgh, Pittsburgh, PA, USA and ${ }^{4}$ Department of Biostatistics, University of Pittsburgh, Pittsburgh, $P A, U S A$

\begin{abstract}
Renal tumors with complex or unusual morphology require extensive workup for accurate classification. Chromosomal aberrations that define subtypes of renal epithelial neoplasms have been reported. We explored if whole-genome chromosome copy number and loss-of-heterozygosity analysis with single nucleotide polymorphism (SNP) arrays can be used to identify these aberrations and classify renal epithelial tumors. We analyzed 20 paraffin-embedded tissues representing clear cell, papillary renal and chromophobe renal cell carcinoma, as well as oncocytoma with Affymetrix GeneChip 10K 2.0 Mapping arrays. SNP array results were in concordance with known genetic aberrations for each renal tumor subtype. Additional chromosomal aberrations were detected in all renal cell tumor types. The unique patterns allowed 19 out of 20 tumors to be readily categorized by their chromosomal copy number aberrations. One papillary renal cell carcinoma type 2 did not show the characteristic 7/17 trisomies. Clustering using the median copy number of each chromosomal arm correlated with histological class when using a restricted set of chromosomes. In addition, three morphologically challenging tumors were analyzed to explore the potential clinical utility of this method. In these cases, the SNP array-based copy number evaluation yielded information with potential clinical value. These results show that SNP arrays can detect characteristic chromosomal aberrations in paraffin-embedded renal tumors, and thus offer a high-resolution, genome-wide method that can be used as an ancillary study for classification and potentially for prognostic stratification of these tumors.
\end{abstract}

Modern Pathology (2008) 21, 599-608; doi:10.1038/modpathol.2008.20; published online 1 February 2008

Keywords: SNP array; chromosome copy number; loss-of-heterozygosity; renal cell carcinoma; oncocytoma

Each year in the United States, there are approximately 31900 cases of kidney and upper urinary tract cancer, which account for approximately $3 \%$ of adult malignancies and result in more than 11900 deaths. ${ }^{1}$ Current classification of renal cell carcinoma is primarily based on histological appearance, the cell type of origin and its growth pattern. The most common malignant types of renal cell carci-

Correspondence: Current address: Dr FA Monzon, MD, The Methodist Hospital, Department of Pathology, 6565 Fannin St MS 205, Houston, TX 77030, USA.

E-mail: famonzon@tmhs.org

*These authors contributed equally to this manuscript.

Received 7 November 2007; revised and accepted 7 January 2008; published online 1 February 2008 noma are clear cell (75\%), papillary (10\%), and chromophobe (5\%). Another common renal neoplasm is oncocytoma, which is a benign renal epithelial tumor thought to arise from intercalated cells. Although the majority of renal cell tumors are of the clear cell or papillary types; there is a subset of renal cell tumors that show morphologic characteristics that preclude their classification into one of the common diagnostic groups included. Assignment of a tumor to the 'renal cell carcinoma, unclassified' category as per the 2004 WHO classification, can be due to the presence of unusual morphologic features, the presence of two or more morphologic types within the same tumor, complete sarcomatoid transformation or predominant oncocytic/granular features which can be present in all 
renal cell carcinoma subtypes. ${ }^{2}$ Immunohistochemistry appears to be a reliable method for routine identification of common variants but fails to resolve oncocytic neoplasms and other less common variants. ${ }^{3}$ Accurate classification of renal cell tumors is important, as different morphologic subtypes require specific therapeutic management due to markedly different prognosis and response to therapy. ${ }^{4}$

Specific genetic abnormalities have been found in different types of renal cell tumors. ${ }^{5}$ The majority of clear cell type renal cell carcinomas have deletions in the short arm of chromosome $3(-3 p)$, while papillary renal cell carcinoma usually presents with trisomies of chromosomes 7 \& 17 and/or loss of chromosome $\mathrm{Y}$, although the frequency of these alterations is lower in papillary type 2 tumors compared with type $1 .{ }^{6}$ Other types of renal cell tumors have deletions or losses on other chromosomes. ${ }^{5}$ Given the presence of characteristic chromosomal aberrations, conventional cytogenetic analysis, fluorescent in situ hybridization (FISH), and array comparative genomic hybridization (CGH) have been used to aid in classification of renal tumors. Karyotyping requires the availability of fresh tissue and has coarse resolution with a detection limit of $>3 \mathrm{Mb}$, thus small chromosomal aberrations are missed by this approach. ${ }^{7}$ FISH offers higher resolution, but with a narrow focus; thus, it can find only what the probes are designed to look for and cannot see what is occurring throughout the genome. Array CGH, which can provide genome-wide copy number information, has been used to classify renal cell tumors by histologic type. ${ }^{8}$

Single nucleotide polymorphism (SNP) arrays were originally designed and applied to genetic association studies, but their use has been successfully extended to the direct detection of structural variations in cancer. ${ }^{9-15}$ The advantages of SNP arrays over other techniques include the ability to assess copy number and genotype in one assay, high resolution, scalability and automation, ease of scoring, single-primer assay methodology, minimal total genomic DNA needed, stringent quality control manufacturing, and relatively low cost. ${ }^{16,17}$ The potential clinical applications for SNP microarrays in cancer diagnostics, prognostics, and therapeutics are evident, and several groups have demonstrated its utility in both fresh and paraffin-embedded tissues. ${ }^{15,18-20}$ Importantly, this technique can detect copy neutral loss of heterozygosity (LOH) events, which comprise $50-70 \%$ of the LOH detected in human tumors. ${ }^{21-23}$ Karyotyping, FISH, and array CGH cannot detect copy neutral LOH lesions.

The goal of this study was to determine if formalin-fixed, paraffin-embedded samples from the four most common subtypes of renal tumors (clear cell, papillary, chromophobe, and oncocytoma) could be classified based on chromosomal copy number aberrations and LOH detected by SNP arrays. We propose that this technique can be used for accurate classification of renal tumors, especially in the setting of complex morphology.

\section{Materials and methods}

\section{Tissue Samples}

Twenty-one FFPE tumor/normal pairs and two tumor samples without matching normal tissues were obtained from the Health Sciences Tissue Bank of the University of Pittsburgh. When available, paired normal tissue was taken from a separate paraffin block that did not contain tumor tissue. The study cohort consisted of five samples from clear cell and chromophobe tumors; six samples from oncocytoma and seven samples from papillary renal cell carcinoma. Samples were de-identified and obtained through an honest broker system with appropriate IRB approval. ${ }^{24}$ Four of these samples (one from each morphologic group) have been reported previously in the manuscript describing the SNP array assay utilized for this study. ${ }^{25}$ Ten $10 \mu \mathrm{m}$ slides and a corresponding hematoxilin and eosin stained slide were obtained for all samples. All cases were reviewed by two pathologists (FAM \& AP) to verify the reported diagnosis. The hematoxilin and eosin stained slides were evaluated by a pathologist (JPB or FAM) for selection of areas to be analyzed in normal and tumor tissues. Three additional samples from renal tumors with a complex morphology (renal cell carcinoma, unclassified) were analyzed separately after all samples in the 'training' cohort were processed.

\section{Sample Preparation and Extraction}

DNA was obtained from four to five $10 \mu \mathrm{m}$ paraffin sections according to a previously described protocol for deparaffinization and DNA extraction. ${ }^{25}$ DNA was quantitated on a NanoDrop ND1000 spectrophotometer (NanoDrop Technologies, Wilmington, DE). All samples processed for downstream analysis in this study had an OD 260/280 ratio higher than 1.8 .

\section{SNP Array Assay}

Samples were processed with a FFPE optimized protocol developed in our lab, based on the GeneChip Mapping $10 \mathrm{~K}$ Xba Assay Kit (Affymetrix, Santa Clara, CA, USA) and whose performance has been described previously. ${ }^{25}$ All samples with 12-20 $\mu \mathrm{g}$ of PCR product were then fragmented and labeled according to the standard Affymetrix Genotyping protocol. The samples were then hybridized on GeneChip ${ }^{\circledR}$ Mapping $10 \mathrm{~K} 2.0$ arrays (Affymetrix, Santa Clara, CA), for $16 \mathrm{~h}$ at $48^{\circ} \mathrm{C}$ in a GeneChip 450 hybridization oven (Affymetrix, Santa Clara, CA) at 60 r.p.m. Once hybridization 
was complete, the used hybridization solution was removed and stored at $-80^{\circ} \mathrm{C}$. The arrays were washed and stained according to the Affymetrix Genotyping protocol. After scanning, quality control for all samples was reviewed prior to data analysis. The data discussed in this publication have been deposited in NCBI's Gene Expression Omnibus (GEO, http://www.ncbi.nlm.nih.gov/geo/) and are accessible through GEO Series accession number GSE9469. ${ }^{26}$

\section{Data Analysis}

Data acquired from the Affymetrix GeneChip Operating System v4.0 (GCOS) was analyzed using Affymetrix GeneChip Genotyping Analysis Software (GTYPE) 4.1. The quality control parameters evaluated for each sample were signal detection rate (the percentage of features in the array that show adequate fluorescence intensity) and the SNP call rate (rate of successful allele identification). ${ }^{18}$ All samples used in downstream analysis had SNP call rates $>85 \%$. LOH and copy number estimates were obtained using a publicly available analysis package: Copy Number Analyzer for Affymetrix GeneChip arrays (CNAG 2.0). ${ }^{16}$ The CNAG algorithm takes into account variation across different experiments and optimizes the selection of best fit references. Copy number estimates for each SNP are based on the $\log 2$ ratios of the signal intensity for the two alleles (all perfect match probes) on the test sample against the reference. Data from the $\mathrm{X}$ chromosome was not analyzed, as the samples were not gender-matched. PCR kinetics contribute to inter-experiment variability, and to compensate for this CNAG performs two quadratic regressions, one for length and one for GC-content of PCR products. The s.d. of the $\log 2$ ratios across the genome is an indicator of the variability of data (noise) within a single array. To further reduce the s.d., CNAG optimizes the reference by averaging multiple samples with the lowest s.d. (selected 'best-fit' references). Copy number inference is done by both local means analysis ( $\log 2$ ratios) and a hidden Markov model in CNAG. Copy number moving average and $\mathrm{LOH}$ likelihood threshold were both set to 20. The range of PCR fragment length for each individual sample was adjusted as recommended by other groups for analysis of DNA derived from formalin-fixed paraffin-embedded tissues. ${ }^{18}$ Further normalization was performed by selecting diploid areas for each sample, as described by CNAG developers. ${ }^{16}$ For the chromophobe carcinoma samples, the diploid region was set based on the results of the allele-specific analysis using selfreference. This is important to avoid artifactual trisomies in hypodiploid samples. We performed hierarchical clustering using the median of $\log 2$ ratios for all SNPs in a chromosomal arm, using Pearson centered distances with centroid linkage rule with the ArrayAssist 5.2.2 software (Stratagene, La Jolla, CA).

For the three samples with complex morphology, a SNP-based diagnosis was rendered by a pathologist not involved in the sample selection/ evaluation (JH). The diagnosis was established by evaluating chromosomal copy number aberrations and $\mathrm{LOH}$ in each sample from the CNAG output and determining the assignment with the following criteria: clear cell carcinoma: $-3 p$, papillary carcinoma: $+7 /+17$, chromophobe carcinoma: $-1,-2$, $-6,-10,-13,-17$ and oncocytoma: -1 , normal or other isolated copy number aberrations. Hierarchical clustering was not used to determine the SNP-based diagnosis.

\section{Results}

\section{Performance of the SNP Array Assay in FFPE Samples}

Twenty-one tumor/normal pairs and two nonmatched tumor samples representing four subtypes of renal tumors were processed with a modified SNP array mapping assay protocol. ${ }^{25}$ All samples yielded adequate DNA quantity for the SNP array assay. Fifteen samples generated good quality array data ( $>85 \%$ SNP call rate) on first attempt, six samples generated good quality data upon repeat and two samples were excluded due to having SNP call rates $<85 \%$ and high s.d. for the $\log 2$ ratio data (papillary carcinoma samples PRCC4 \& PRCC7). One case of oncocytoma was excluded from the study because it belonged to a patient with familial oncocytosis and did not represent a common case of sporadic oncocytoma (OC3). Thus the final cohort had five samples from each diagnostic group. Characteristics of tumor samples used in this study are presented in Table 1.

\section{Chromosome Copy Number Aberrations and LOH}

The chromosomal copy number aberrations and loci of $\mathrm{LOH}$ derived using the SNP arrays were in agreement with those reported in the literature for each subtype and are summarized in Table 2 . An example of a whole genome display from a characteristic sample from each group is shown in Figure 1 and whole genome displays for all samples are shown in Supplementary Figures 1-4. Loss of all or part of the short arm of chromosome 3 is a distinctive feature of clear cell tumors, and was detected in all five samples from this group by the SNP arrays. Four out of five papillary carcinoma samples demonstrated the characteristic trisomies of chromosomes 7 and 17, while one papillary tumor failed to show these aberrations and showed other chromosomal changes. The chromophobe carcinoma cohort showed losses affecting multiple chromosomes. Oncocytomas showed either no detectable chromosome copy number aberrations, 
Table 1 Characteristics of tumor samples

\begin{tabular}{|c|c|c|c|c|c|}
\hline Sample ID & Diagnosis & Size $(\mathrm{cm})$ & Fuhrman nuclear grade & TNM stage & Matched normal \\
\hline CHRCC1 & Renal cell carcinoma, chromophobe & 7.7 & 2 & $\mathrm{~T} 2 \mathrm{NxMx}$ & Yes \\
\hline CHRCC2 & Renal cell carcinoma, chromophobe & 9.7 & 3 & $\mathrm{~T} 2 \mathrm{NxMx}$ & Yes \\
\hline CHRCC3 & Renal cell carcinoma, chromophobe & 5.5 & 3 & $\mathrm{~T} 1 \mathrm{NxMx}$ & Yes \\
\hline CHRCC4 & Renal cell carcinoma, chromophobe & 7.0 & 3 & T3bNxMx & Yes \\
\hline CHRCC5 & Renal cell carcinoma, chromophobe & 6.0 & 2 & T1bNxMx & Yes \\
\hline CRCC1 & Renal cell carcinoma, clear cell & 4.0 & 2 & T1aNxMx & Yes \\
\hline CRCC2 & Renal cell carcinoma, clear cell & 6.0 & 2 & T1bNxMx & Yes \\
\hline CRCC3 & Renal cell carcinoma, clear cell & 5.4 & 2 & T1bNxMx & Yes \\
\hline CRCC4 & Renal cell carcinoma, clear cell & 4.5 & 3 & T1bNxMx & Yes \\
\hline CRCC5 & Renal cell carcinoma, clear cell & 5.2 & 2 & T1bNxMx & Yes \\
\hline OC1 & Oncocytoma & 2.8 & N/A & N/A & Yes \\
\hline OC2 & Oncocytoma & 5.5 & N/A & N/A & Yes \\
\hline OC4 & Oncocytoma & 4.0 & N/A & N/A & Yes \\
\hline OC5 & Oncocytoma & 1.5 & N/A & N/A & No \\
\hline OC6 & Oncocytoma & 21.0 & N/A & N/A & Yes \\
\hline PRCC1 & Renal cell carcinoma, papillary type 1 & 5.3 & 3 & T1bNxMx & Yes \\
\hline PRCC2 & Renal cell carcinoma, papillary type 2 & 4.3 & 3 & T1bNxMx & Yes \\
\hline PRCC3 & Renal cell carcinoma, papillary type 2 & 2.2 & 3 & T1aNxMx & No \\
\hline PRCC5 & Renal cell carcinoma, papillary type 1 & 8.5 & 3 & $\mathrm{~T} 2 \mathrm{NxMx}$ & Yes \\
\hline PRCC6 & Renal cell carcinoma, papillary type 1 & 4.5 & 2 & T1bNxMx & No \\
\hline
\end{tabular}

Table 2 Chromosomal abnormalities of renal cell tumor subtypes

\begin{tabular}{|c|c|c|c|}
\hline Type of renal tumor & $\begin{array}{l}\text { Classic cytogenetic } \\
\text { findings }^{\mathrm{a}}\end{array}$ & $\begin{array}{l}\text { Classic } \\
\text { findings } \\
\text { detected }\end{array}$ & Chromosome copy number aberrations detected ${ }^{\mathrm{b}}$ (cases) \\
\hline $\begin{array}{l}\text { Clear cell renal cell } \\
\text { carcinoma }\end{array}$ & $\begin{array}{l}\operatorname{del}(3)(\mathrm{p}) ; \text { especially } 3 \mathrm{p} 21 \\
3 \mathrm{p} 25-26 \text { (VHL gene) }\end{array}$ & $5 / 5$ & $\begin{array}{l}\operatorname{del}(3)(p)[5], \operatorname{dup}(3)(q)[1],+5[2], \operatorname{dup}(5)(q)[2],-6[1],+7[2], \operatorname{del}(8)(q) \\
{[1],-9[2],-10[2],+12[1],-14[2],+16[1],-16[1],-17[1],-19[1]}\end{array}$ \\
\hline $\begin{array}{l}\text { Papillary renal cell } \\
\text { carcinoma }\end{array}$ & Trisomy 7 and 17 & $4 / 5$ & $\begin{array}{l}-1[1],+1 p[1],+3[2], \operatorname{dup}(3)(q)[1],+7[4] . \operatorname{del}(8)(p)[1], \operatorname{dup}(8)(q)[1], \\
+12[1], \operatorname{dup}(12)(q)[3],-14[1],-15[1],+\mathbf{+ 1 7}[4],+16[3],+19[2], \\
\operatorname{dup}(20)(q)[2],+21[1]\end{array}$ \\
\hline $\begin{array}{l}\text { Chromophobe } \\
\text { renal cell } \\
\text { carcinoma }\end{array}$ & $\begin{array}{l}\text { Multiple losses of entire } \\
\text { chromosomes }\end{array}$ & $5 / 5$ & $\begin{array}{l}-\mathbf{1}[4], \operatorname{del}(1)(\mathrm{p})[1],-\mathbf{2}[\mathbf{5}],-\mathbf{6}[\mathbf{5}],-8[1],-10[4],-13[4],-\underline{\mathbf{1 7}[5]}, \\
\operatorname{del}(19)(\mathrm{q})[1],[1] \operatorname{del}(20)(\mathrm{q}) \\
{[1],-21}\end{array}$ \\
\hline Oncocytoma & $\begin{array}{l}\text { No karyotypic } \\
\text { abnormalities or chr } 1 \\
\text { aberrations }\end{array}$ & $5 / 5$ & $\begin{array}{l}-1[1], \operatorname{del}(1)(p)[2], \operatorname{del}(1)(q)[1], \operatorname{dup}(1)(p)[1], \operatorname{dup}(1)(q)[1], \operatorname{dup}(17)(q) \\
{[1],+19[1]}\end{array}$ \\
\hline
\end{tabular}

${ }^{\mathrm{a}}$ Adapted from the atlas of genetics and cytogenetics in oncology and haematology. URL http://AtlasGeneticsOncology.org ${ }^{27}$

${ }^{b}$ Exact size of deletion/duplications is not given. Bold and underlined aberrations are those characteristic of the diagnostic group.

losses in chromosome 1 or trisomy 19. Confirmation of copy number changes (by array CGH) and $\mathrm{LOH}$ (by microsatellite analysis) on a representative sample from each subtype has been reported previously. ${ }^{25}$

In addition to the characteristic changes reported, the SNP arrays identified additional copy number aberrations in the majority of these tumors (Table 2). Four of the five clear cell tumor samples showed trisomy or partial gain of chromosomes 5 and two samples showed trisomy 7. Each tumor had other unique chromosomal aberrations detected. The papillary tumors also showed trisomy or partial trisomy of chromosome 5, in addition to the characteristic trisomy $7 / 17$. The papillary tumor without trisomy 7/17 showed monosomies for chromosomes 1, 14 and 15 and trisomies of 16, 19 and 21 with partial gains in chromosomes 20 and 22 . This papillary tumor corresponded to type 2 histology. One of the chromophobe carcinoma samples, CHRCC5, displayed some, but not all of the characteristic losses seen in the other four chromophobe RCCs in this study, in this case, there was partial loss of chromosome 1 and no losses of chromosomes 10 and 13 . This case had no specific morphologic features that could distinguish it from other chromophobe RCCs. There was no association between Fuhrman nuclear grade and specific chromosomal aberrations in any of the RCC subtypes. Oncocytomas showed very few copy number aberrations, with no repeating pattern, except for partial or complete loss of chromosome 1. 
a

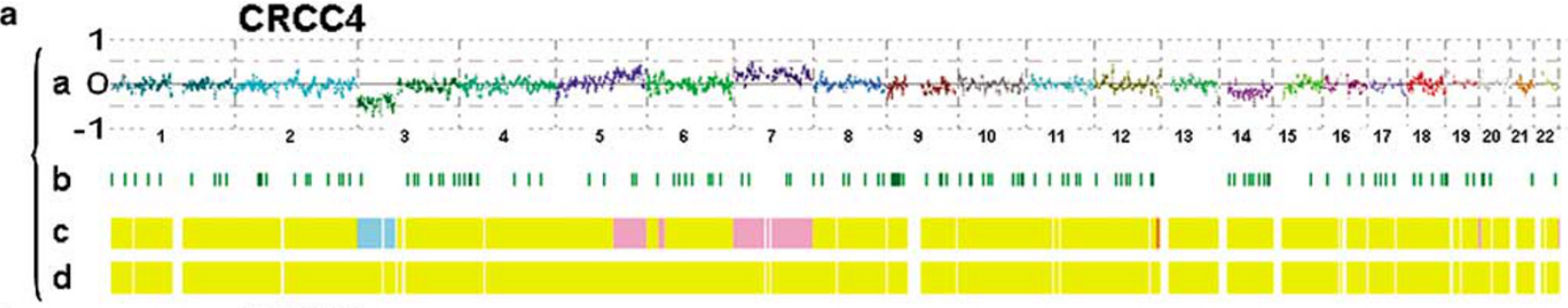

b

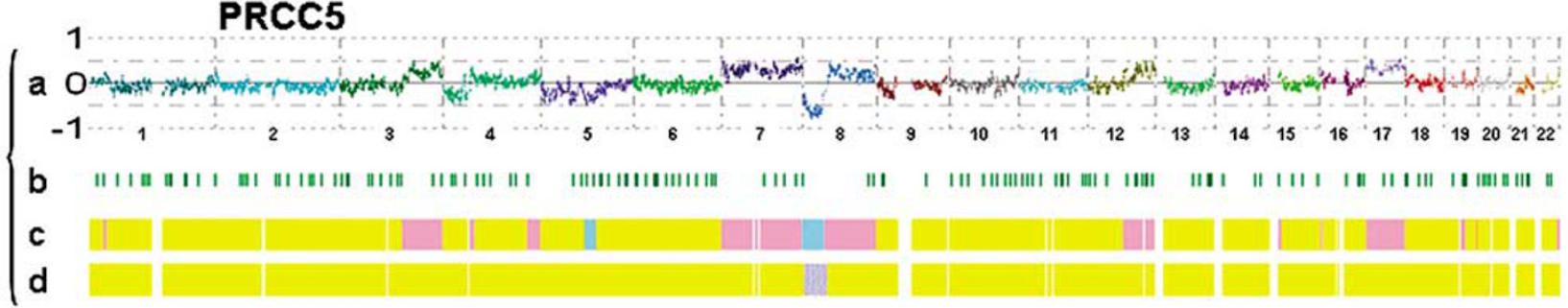

C

CHRCC4

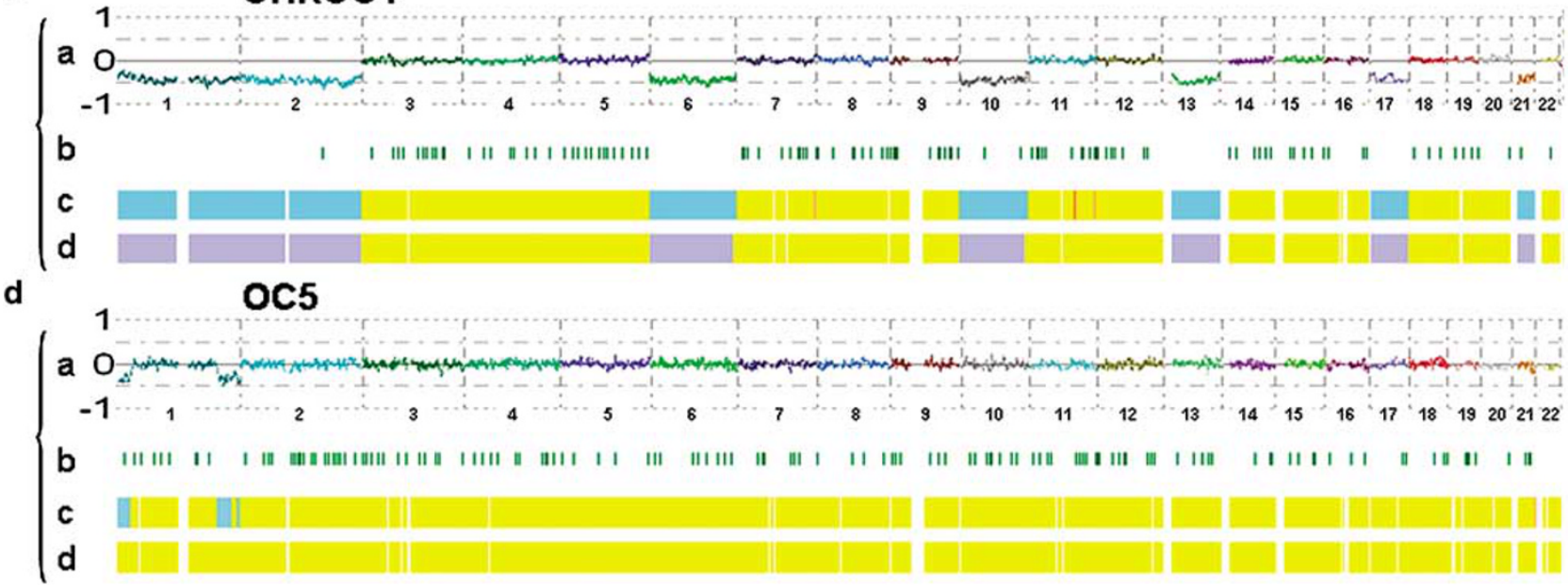

Figure 1 Chromosome copy number analysis and $\mathrm{LOH}$ in renal epithelial tumors. Whole genome view of genetic aberrations seen in representative samples from each of the morphologic groups as displayed by the CNAG software. A-Clear Cell, B-Papillary and C-Chromophobe renal cell carcinomas; D-Oncocytoma. Chromosomes are color-coded and sequential along the $x$ axis. The uppermost plot for each sample represents the estimated copy number as a log 2 ratio averaged over 20 SNPs (a), thus the zero line indicates a copy number of two and deviations up or down represent gains or losses. The dark green bars (b) are heterozygous calls in the tumor. The upper yellow bar (c) represents the copy number data in a color-coded Hidden Markov Model (yellow = copy number 2, pink $=$ copy number 3, aqua = copy number 1). The lower yellow bar for each sample (d) represents the hidden Markov model for LOH likelihood (yellow $=$ no $\mathrm{LOH}$, the more blue the bar = the more likely the $\mathrm{LOH}$ in that region).

We performed hierarchical clustering on the median of the $\log 2$ ratios for all SNPs in a chromosomal arm. As shown in Figure 2a, all samples in the chromophobe and clear cell groups show distinct clusters. All papillary carcinomas with trisomy $7 / 17$ formed a separate cluster that included oncocytoma sample OC6. Interestingly, both this sample (OC6) and one of the papillary carcinoma samples showed focal gains in $1 p$ and trisomy 19 (see Supplementary Figures 2 and 4). Oncocytoma samples with monosomy 1 are seen separate along with papillary carcinoma sample PRCC3, which also has monosomy 1. OC1 (labeled OC in Figure) does not belong to any cluster. When only chromosomal arms that show gain/loss in a single group were considered in the clustering algorithm (Figure 2b; chromosomes 2, 3p, 5, 6,
7 and 17), well-defined clusters for clear cell, chromophobe and papillary tumors are seen. By focusing on these chromosomes, clear separation of OC6 from the papillary carcinoma group $(+7 /+17)$ is achieved. As expected, papillary carcinoma sample PRCC3 does not cluster with the rest of the samples in the papillary carcinoma group.

\section{Application to Morphologically Challenging Tumors}

In the initial cohort, all tumors had a definitive diagnosis based on morphology, as confirmed by two pathologists. As a proof of concept to investigate the utility of this approach in clinical practice, we applied this strategy to three cases of renal neoplasms where a subclassification of the renal 
a

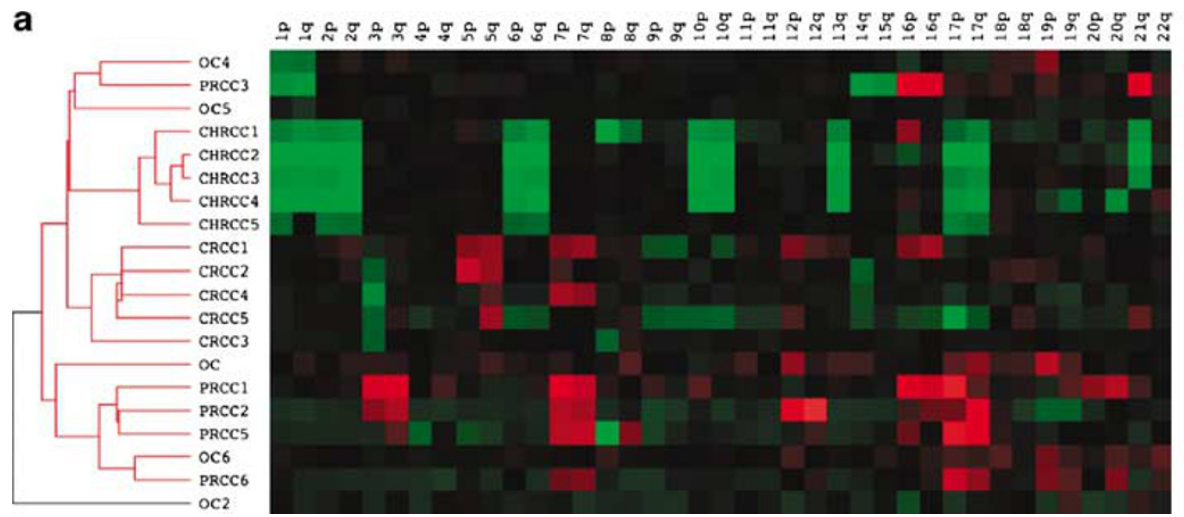

b

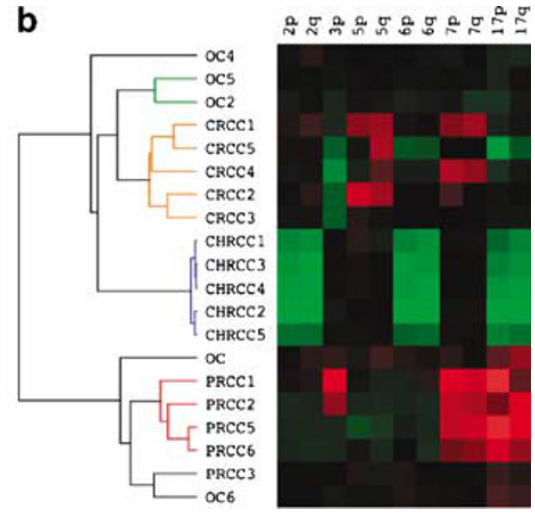

Figure 2 (a) Hierarchical clustering of four subtypes of renal tumors. The median $\log 2$ ratios (estimated copy number) for all chromosomal arms are clustered using Pearson centered distances with centroid linkage rule. Green represents chromosomal loss and red represents chromosomal gains. (b) Hierarchical clustering restricted to chromosomes 2, 3(p arm only), 5, 6, 7 \& 17, which are chromosomes that show more consistent changes among groups. Note shorter distances between members of each group in the dendogram.

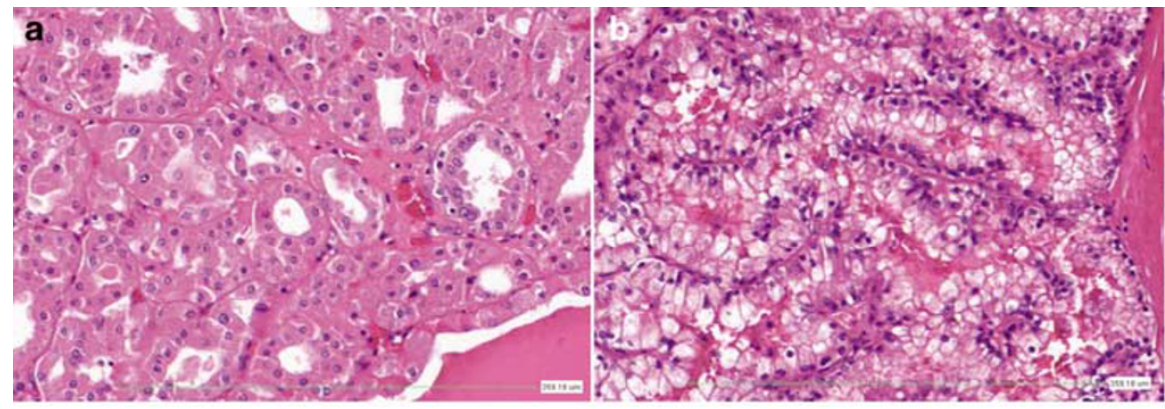

d

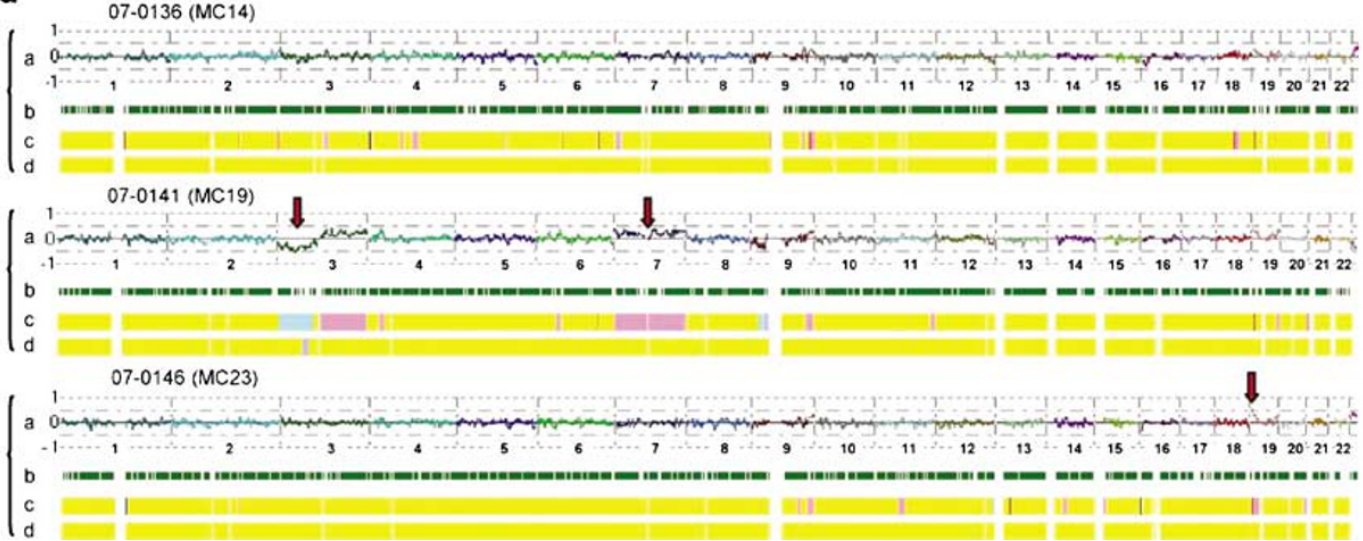

e

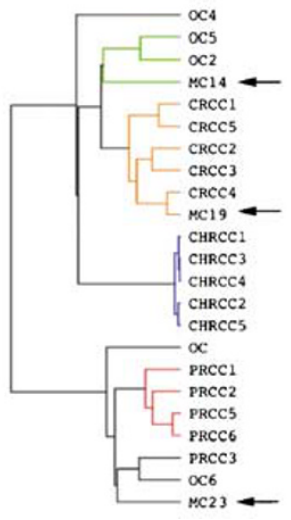

Figure 3 (a-c) Microscopic appearance of tumors included in the morphologically challenging group or renal tumors. (hematoxilin and eosin stain, X200 magnification) a: MC14, b: MC19 and c: MC23. (d) Whole genome view of genetic aberrations seen in these tumors. Note absence of significant copy number change aberrations in MC14, del(3)(p) and + 5 in MC19 (arrows) and dup(19)(p) in MC23 (arrow). (e) Dendogram from clustering analysis with the restricted chromosome set (see Figure 2) with morphologically challenging samples (arrows).

tumor could not be definitively rendered based on morphology and other ancillary studies such as immunohistochemistry and/or FISH (Figure 3 and Table 3). As shown in Figure 3d, in all three cases, the SNP array results unambiguously detected the presence or absence of chromosomal aberrations characteristic of one of the four renal epithelial groups studied in the initial cohort. Clustering analysis of these samples with the focused chromosome data (2, 3p, 5, 6, $7 \& 17)$ along with the 20 renal tumors with unambiguous diagnoses from the initial cohort shows sample MC14 clustered with the oncocytoma samples OC2 and OC5, consistent with the absence of copy number aberrations in this sample. MC19 shows the presence of 3p- and thus it clusters closely with the clear cell group (Figure 3e). 
Table 3 Application of chromosome copy number analysis to morphologically challenging cases

\begin{tabular}{|c|c|c|c|c|c|}
\hline Sample & Morphology & $I H C$ & FISH & Final diagnosis & SNP array \\
\hline $\begin{array}{l}07 \_0136 \\
\text { (MC14) }\end{array}$ & $\begin{array}{l}6.0 \mathrm{~cm} \text { eosinophilic neoplasm } \\
\text { with tubular and nesting } \\
\text { architecture with scant stroma. } \\
\text { Prominent vascular pattern and } \\
\text { focal perinuclear clearing. } \\
\text { Colloidal iron positive. }\end{array}$ & $\begin{array}{l}\text { Positive for CD10, } \\
\text { Inhibin, BerEP4, E- } \\
\text { Cadherin, Vimentin } \\
\text { and Cytokeratin } 7\end{array}$ & $\begin{array}{l}\text { Monosomy } \\
1,2,7 \text { and } 17\end{array}$ & $\begin{array}{l}\text { Chromophobe renal cell } \\
\text { carcinoma }\end{array}$ & $\begin{array}{l}\text { No } \\
\text { chromosomal } \\
\text { aberrations/ } \\
\text { Oncocytoma }\end{array}$ \\
\hline $\begin{array}{l}07 \_0141 \\
\text { (MC19) }\end{array}$ & $\begin{array}{l}\text { Multiple synchronous papillary } \\
\text { and clear cell tumors. This } \\
\text { tumor showed papillary } \\
\text { architecture with granular and } \\
\text { clear cell features. Prominent } \\
\text { cell membranes. Colloidal } \\
\text { iron positive. }\end{array}$ & $\begin{array}{l}\text { Positive for RCC, } \\
\text { CD10, Vimentin, CK7 } \\
\text { (focal), Inhibin (weak), } \\
\text { BerEP4, E-Cadherin } \\
\text { (weak) }\end{array}$ & $\begin{array}{l}\text { Monosomy } \\
1,2 \text { and } 7\end{array}$ & $\begin{array}{l}\text { Chromophobe renal cell } \\
\text { carcinoma with comment } \\
\text { indicating immunostain } \\
\text { results suggest clear cell } \\
\text { origin }\end{array}$ & $\begin{array}{l}-3 p,+3 q,+7 \\
-9 p \text { Renal cell } \\
\text { carcinoma, clear } \\
\text { cell type }\end{array}$ \\
\hline $\begin{array}{l}07 \_0146 \\
(\mathrm{MC} 23)\end{array}$ & $\begin{array}{l}6.0 \mathrm{~cm} \text { eosinophilic neoplasm } \\
\text { with nesting and tubular } \\
\text { architecture. Prominent cellular } \\
\text { discohesion with scant stroma. }\end{array}$ & $\begin{array}{l}\text { Positive for } \\
\text { parvalbumin, E- } \\
\text { cadherin, Ber-EP4, } \\
\text { colloidal iron, CK7 } \\
\text { and CD10 }\end{array}$ & $\begin{array}{l}\text { Monosomy } 1 \text {, } \\
2,7 \text { and } 17\end{array}$ & $\begin{array}{l}\text { Eosinophilic renal cell } \\
\text { carcinoma, with comment } \\
\text { indicating that ancillary } \\
\text { studies suggest a } \\
\text { chromophobe type }\end{array}$ & $\begin{array}{l}+19 p \\
\text { Oncocytoma }\end{array}$ \\
\hline
\end{tabular}

In addition, this sample shows trisomy 7, also observed in other clear cell samples. MC23 shows only focal copy number increase in chromosome 19, a pattern most consistent with the oncocytoma group. Interestingly, in the clustering algorithm, this sample does not show close similarity to others.

\section{Discussion}

Renal cell carcinomas are a morphologically and clinically heterogeneous group of neoplasms arising from the renal tubular epithelium. Morphological distinction among these subtypes is generally straightforward. However, a subset of cases may be morphologically complex and require ancillary studies for classification. Although the chromosomal aberrations that characterize each subtype of renal epithelial neoplasms have been known for some time, this knowledge is not routinely used in the diagnostic evaluation of these tumors. Pathologists often rely on immunohistochemistry and in some cases FISH to aid in the classification and prognostic stratification of morphologically challenging renal tumors. Immunohistochemistry is usually helpful; however many cases can show noncharacteristic profiles. ${ }^{3}$ Given the clinical relevance of accurately classifying patients for prognostic implications and therapeutic decisions, ${ }^{4}$ there is a need for diagnostic tools that reliably detect and quantify genetic variations diagnostic for each subgroup. Our results show the potential utility of SNP arrays in the routine clinical evaluation of renal epithelial tumors, especially those that do not present characteristic morphologic features that allow a definitive diagnosis on routine surgical pathology examination.
Alternative methods of detecting chromosomal aberrations are available, such as karyotyping, FISH, SKY, CGH and array CGH. Of these, only FISH, array CGH and SNP arrays are best suited for routine clinical use with paraffin embedded tissues. We have chosen the SNP array platform for its genomewide coverage, the ability to assess copy number and genotype in one assay, the ability to use paraffin-embedded tissues, the ability to detect copy neutral $\mathrm{LOH}$ and reduced cost. These are all significant advantages of copy number analysis with SNP arrays when compared to other methods. Like array CGH, SNP arrays cannot detect inversions and translocations. However, with exception of the translocations involving Xp11.2 in renal cell tumors from young patients, ${ }^{28}$ chromosomal translocations do not seem to play a significant role in the pathogenesis of the most common subtypes of renal tumors.

We have previously shown that SNP arrays can reliably detect chromosome copy number aberrations and $\mathrm{LOH}$ in paraffin-embedded tissues with the use of an optimized protocol. ${ }^{25}$ In this manuscript, we have analyzed 47 paraffin-embedded tissue samples from routine archival material (26 tumor and 21 normal specimens) and 45 of them yielded good quality data, which confirms the reliability and performance of this method with clinical samples. The SNP array call rates obtained with the renal tumor samples are well within those accepted as adequate for copy number analysis in paraffin-embedded tissue with this technology $\left(70-90 \%\right.$ call rates), ${ }^{19,29}$ and for reliable $\mathrm{LOH}$ analysis. ${ }^{25}$ Furthermore, copy number aberrations and LOH detected by the SNP arrays were in agreement with the genetic abnormalities described in the literature for the different types of renal 
epithelial tumors. ${ }^{27}$ These characteristic patterns of chromosomal aberrations permit classification of each sample based on the presence of $3 p$ deletions in clear cell renal cell carcinoma, trisomy $7 \& 17$ in papillary renal cell carcinoma, losses of chromosomes 1, 2, 6, 10, 13 and 17 in chromophobe renal cell carcinoma and monosomy 1 , no aberrations or chromosome 19 aberrations in oncocytomas. One case of papillary carcinoma with type 2 histology did not show the characteristic trisomy $7 / 17$ for this group. It has been previously demonstrated that these chromosomal aberrations are much less frequent in papillary type 2 tumors and thus this result is not entirely unexpected. ${ }^{6,30}$ This highlights the necessity of expanding the study to more renal cell tumors with whole genome analysis to define the frequency of this pattern in the papillary type 2 carcinoma group. It is important to note that the detection of copy number aberrations in tumors can be complicated by the presence of normal tissue (normal contamination), which can lead to false negatives. The ability to macrodissect tissue from a paraffin embedded section permitted us to minimize normal tissue contamination.

Importantly, our study has only 20 cases from the most common types of renal neoplasms and does not include all other, less frequent, sub-types of renal tumors (including the two papillary subtypes). However, the patterns of chromosomal gains/losses we observed confirm the presence of these aberrations in the four tumor subtypes studied and illustrate how this genomic information can be of diagnostic utility. Studies to expand our cohort of these tumor types and to analyze other less common subtypes are underway. An advantage of using a genome-wide strategy is the possibility of detecting additional aberrations that would have been missed by routine FISH panels or LOH analysis. As shown in Table 2 and the Supplementary information, we identified chromosomal abnormalities, in addition to those expected in the specific tumor type, in almost all cases or renal cell carcinoma. Most of the additional chromosomal abnormalities found in this study are in agreement with published findings and some have been associated with aggressive behavior or progression. ${ }^{27}$ Our results confirm that additional copy number aberrations are quite frequent and although we have a relatively small set of samples, some of these lesions seem to define specific subsets of tumors (eg clear cell carcinoma with $+5 /+5 p$ ). Also, isolated chromosomal aberrations were seen in two oncocytomas, partial gain of chromosome 7 and trisomy 19. Interestingly, the oncocytoma with +19 represents a $21 \mathrm{~cm}$ oncocytoma. Presumably, this fairly large tumor has had a long growth period and thus it is possible that this aberration reflects an acquired genetic change during this long period. At this point, it is not known whether these tumor subsets are clinically relevant. It is possible that these abnormalities could account for variations in tumor aggressiveness and/or response to the therapy. It is important to note that as many as $30 \%$ of surgically treated patients develop metastases $^{31}$ and approximately $20 \%$ of T2 tumors (organ confined) show disease-related mortality which cannot be accounted by histologic grade. ${ }^{32}$ Retrospective analysis of more renal cell tumors in this category, with whole genome SNP arrays, will allow us to determine if these copy number aberrations are associated with prognosis and/or therapeutic response.

To explore the use of this technique in the diagnostic workup of morphologically challenging renal tumors, we analyzed three cases where the final classification after routine pathology was not definitive (renal cell carcinoma, unclassified). Two of the cases consisted of eosinophilic neoplasms with features of chromophobe carcinoma (such as perinuclear clearing and colloidal iron positivity) along with features of oncocytoma (nesting pattern) (Samples MC14 and MC23, Table 3). These cases illustrate a common differential diagnosis between oncocytoma and eosinophilic variant of chromophobe renal cell carcinoma. This situation is of particular importance, since it involves the distinction between a malignant neoplasm (albeit with good prognosis) and a benign tumor, with significant medical and psychological implications. Immunohistochemistry is of limited utility in this situation, since staining patterns for these two neoplasms are quite similar. ${ }^{3}$ As reported previously by Brunelli and colleagues, detection of losses of chromosomes $2,6,10$, or 17 effectively excludes the diagnosis of oncocytoma and supports the diagnosis of chromophobe renal cell carcinoma. ${ }^{33}$ Our results show that the $10 \mathrm{~K} 2.0 \mathrm{SNP}$ array results can reliably distinguish between oncocytoma and chromophobe renal cell carcinoma in a single assay with DNA obtained from formalin-fixed paraffin-embedded tissue. The chromophobe carcinoma group shows losses affecting multiple chromosomes thereby providing a constellation of chromosomal aberrations, which readily distinguish chromophobe tumors from other types of renal epithelial neoplasms. In the third case (MC19), the consideration is of a tumor with mixed papillary architecture and clear cell morphology with granular features in a patient with multiple bona fide clear cell and papillary tumors. No family history or cancer was disclosed to the pathologist. This is a complex case where the differential diagnosis includes clear cell, papillary and chromophobe renal cell carcinoma. The diagnosis of mixed tumors (renal cell carcinoma, unclassified) is not an uncommon situation, which has implications in prognosis and therapeutic decisions. In this case, positive RCC antigen and CD10 suggest that this tumor could be of clear cell origin but the CK7, BerEp4 and colloidal iron positivity, along with the morphologic features precluded the pathologist from issuing a definitive classification, since these are features of papillary and chromophobe carcinomas. The chromosome copy number analysis with 
SNP array clearly identified chromosomal loss at $3 p$ and confirms that this tumor is a clear cell renal cell carcinoma. These real-life examples are indicative of how this assay could be incorporated in everyday clinical practice for the pathologic evaluation of renal epithelial neoplasms.

Although it is common for ancillary studies to have subjective interpretations rendered by experienced pathologists and technicians, the results from the chromosome copy number analysis with SNP arrays are easy to interpret. Furthermore, the output can be readily related to a conventional karyotype, so clinicians and pathologists are already familiar with chromosome copy number information and its meaning. In addition, we explored the use of hierarchical clustering using the median copy number of each chromosomal arm for sample classification. Although hierarchical clustering is useful as another way of visualizing our results, this tool failed to adequately resolve the oncocytoma group, despite the fact that this group shows absence of characteristic chromosomal aberrations present in other tumor types. We believe that the interpretation can be performed based on the actual copy number/LOH data, along with clinical history, morphology and other studies. By reviewing a whole genome view of the copy number analysis, a pathologist can quickly and reliably recognize chromosome copy number/LOH patterns associated with one of the diagnostic groups. It is important to mention, that for this technology to become the basis of a clinically accepted test, it will be necessary to perform validation studies with larger patient cohorts that adequately represent the frequency of the characteristic chromosomal aberrations in each diagnostic group. Also, correlation with outcome data will be paramount for understanding the diagnostic, prognostic and therapeutic implication of genomic changes in renal tumors.

In summary, our results show that chromosome copy number changes detected by SNP arrays can produce information that a pathologist can use to reliably classify renal tumors into the four most common diagnostic entities. Furthermore, we have applied this technique to a limited number of morphologically challenging cases that could not be resolved by routine pathology but showed characteristic chromosomal abnormalities that would allow classification. These results indicate that, if validated with a larger sample cohort, detection of chromosomal copy number aberrations with SNP arrays has the potential to be a significant aid in the diagnosis and prognostic stratification of renal epithelial tumors.

\section{Acknowledgements}

We acknowledge the Health Sciences Tissue Bank at the University of Pittsburgh for their help in retrieving tissue samples and de-identified patient information. We also thank George Tseng from the School of Public Health, University of Pittsburgh and Leif Peterson from The Methodist Hospital Research Institute for helpful discussions on data analysis and clustering. Partially supported by the University of Pittsburgh Cancer Institute, Cancer Center Support Grant 5P30CA047904-18 NCI/NIH (Ronald Herberman PI) and internal funds from the Department of Pathology, University of Pittsburgh.

\section{References}

1 DeVita VT, Hellman S, Rosenberg SA. Cancer, Principles and Practice of Oncology, 6th edn. Lippincott, Williams \& Wilkins: Philadelphia, 2001, 2 v. (lxxii, 3235, 164 p).

2 Eble JN, World Health Organization, International Agency for Research on Cancer, International Academy of Pathology. Pathology and Genetics of Tumours of the Urinary System and Male Genital Organs. IARC Press: Lyon; Oxford University Press (distributor): Oxford, 2004.

3 Balani JP, Catroppo JF, McHale T, et al. Immunohistochemical profile of renal epithelial neoplasms: an institutional experience with 92 consecutive cases. Mod Pathol 2006;19:129A.

4 Herrmann E, Brinkmann OA, Bode ME, et al. Histologic subtype of metastatic renal cell carcinoma predicts response to combined immunochemotherapy with interleukin 2, interferon alpha and 5-fluorouracil. Eur Urol 2007;51:1625-1631.

5 Polascik TJ, Bostwick DG, Cairns P. Molecular genetics and histopathologic features of adult distal nephron tumors. Urology 2002;60:941-946.

6 Jiang F, Richter J, Schraml P, et al. Chromosomal imbalances in papillary renal cell carcinoma: genetic differences between histological subtypes. Am J Pathol 1998;153:1467-1473.

7 Feuk L, Carson AR, Scherer SW. Structural variation in the human genome. Nat Rev Genet 2006;7:85-97.

8 Wilhelm M, Veltman JA, Olshen AB, et al. Array-based comparative genomic hybridization for the differential diagnosis of renal cell cancer. Cancer Res 2002;62:957-960.

9 Bignell GR, Huang J, Greshock J, et al. High-resolution analysis of DNA copy number using oligonucleotide microarrays. Genome Res 2004;14:287-295.

10 Huang J, Wei W, Zhang J, et al. Whole genome DNA copy number changes identified by high density oligonucleotide arrays. Hum Genomics 2004;1: 287-299.

11 Gibbs JR, Singleton A. Application of genome-wide single nucleotide polymorphism typing: simple association and beyond. PLoS Genet 2006;2:1-7.

12 Janne PA, Li C, Zhao X, et al. High-resolution singlenucleotide polymorphism array and clustering analysis of loss of heterozygosity in human lung cancer cell lines. Oncogene 2004;23:2716-2726.

13 Lindblad-Toh K, Tanenbaum DM, Daly MJ, et al. Loss-of-heterozygosity analysis of small-cell lung carcinomas using single-nucleotide polymorphism arrays. Nat Biotechnol 2000;18:1001-1005.

14 Rauch A, Ruschendorf F, Huang J, et al. Molecular karyotyping using an SNP array for genomewide genotyping. J Med Genet 2004;41:916-922. 
15 Zhou X, Mok SC, Chen Z, et al. Concurrent analysis of loss of heterozygosity (LOH) and copy number abnormality (CNA) for oral premalignancy progression using the Affymetrix 10K SNP mapping array. Hum Genet 2004;115:327-330.

16 Nannya Y, Sanada M, Nakazaki K, et al. A robust algorithm for copy number detection using high-density oligonucleotide single nucleotide polymorphism genotyping arrays. Cancer Res 2005;65: 6071-6079.

17 Zhou X, Rao NP, Cole SW, et al. Progress in concurrent analysis of loss of heterozygosity and comparative genomic hybridization utilizing high-density single nucleotide polymorphism arrays. Cancer Genet Cytogenet 2005;159:53-57.

18 Thompson ER, Herbert SC, Forrest SM, et al. Whole genome SNP arrays using DNA derived from formalinfixed, paraffin-embedded ovarian tumor tissue. Hum Mutat 2005;26:384-389.

19 Jacobs S, Thompson ER, Nannya Y, et al. Genomewide, high-resolution detection of copy number, loss of heterozygosity, and genotypes from formalin-fixed, paraffin-embedded tumor tissue using microarrays. Cancer Res 2007;67:2544-2551.

20 Lindblad-Toh K, Tanenbaum DM, Daly MJ, et al. Loss-of-heterozygosity analysis of small-cell lung carcinomas using single-nucleotide polymorphism arrays. Nat Biotechnol 2000;18:1001-1005.

21 Beroukhim R, Lin M, Park Y, et al. Inferring loss-ofheterozygosity from unpaired tumors using highdensity oligonucleotide SNP arrays. PLoS Comput Biol 2006;2:e41.

22 Huang J, Wei W, Zhang J, et al. Whole genome DNA copy number changes identified by high density oligonucleotide arrays. Hum Genomics 2004;1: 287-299.

23 Ishikawa S, Komura D, Tsuji S, et al. Allelic dosage analysis with genotyping microarrays. Biochem Biophys Res Commun 2005;333:1309-1314.
24 Patel A, Gilbertson J, Parwani A, et al. An informatics model for tissue banks-lessons learned from the Cooperative Prostate Cancer Tissue Resource. BMC Cancer 2006;6:120.

25 Lyons-Weiler M, Hagenkord J, Sciulli CM, et al. Optimization of the Affymetrix GeneChip mapping 10K 2.0 assay for routine clinical use on formalin-fixed paraffin-embedded tissues. Diagn Mol Pathol 2008; 17:3-13.

26 Barrett T, Troup DB, Wilhite SE, et al. NCBI GEO: mining tens of millions of expression profilesdatabase and tools update. Nucleic Acids Res 2007;35:D760-D765.

27 van den Berg E, Storkelvan S. Kidney: renal cell carcinoma. Atlas Genet Cytogenet Oncol Haematol 2003; http://AtlasGeneticsOncology.org/ Tumors/RenalCellCarcinID5021.html.

28 Argani P, Ladanyi M. Translocation carcinomas of the kidney. Clin Lab Med 2005;25:363-378.

29 Affymetrix. Copy number and genotype analysis of FFPE-extracted DNA. Affymetrix Inc.: Santa Clara, CA, 2007, Technical note.

30 Gunawan B, von Heydebreck A, Fritsch T, et al. Cytogenetic and morphologic typing of 58 papillary renal cell carcinomas: evidence for a cytogenetic evolution of type 2 from type 1 tumors. Cancer Res 2003;63:6200-6205.

31 Cohen HT, McGovern FJ. Renal-cell carcinoma. N Engl J Med 2005;353:2477-2490.

32 Zisman A, Pantuck AJ, Wieder J, et al. Risk group assessment and clinical outcome algorithm to predict the natural history of patients with surgically resected renal cell carcinoma. J Clin Oncol 2002;20:4559-4566.

33 Brunelli M, Eble JN, Zhang S, et al. Eosinophilic and classic chromophobe renal cell carcinomas have similar frequent losses of multiple chromosomes from among chromosomes 1, 2, 6, 10, and 17, and this pattern of genetic abnormality is not present in renal oncocytoma. Mod Pathol 2005;18:161-169.

Supplementary information accompanies the paper on Modern Pathology website (http://www.nature.com/ modpathol) 